A revised version of this paper is to be published in Journal of Alternative Investments

\title{
How Active is Your Real Estate Fund Manager?
}

\author{
Martijn Cremers \\ Professor of Finance \\ Mendoza College of Business \\ University of Notre Dame \\ Notre Dame, IN 46556, U.S.A. \\ Phone: +1-574-631-4476 \\ Email: mcremers@nd.edu \\ Colin Lizieri \\ Grosvenor Professor of Real Estate Finance \\ Department of Land Economy \\ University of Cambridge \\ 19 Silver Street, Cambridge, CB3 9EP, U.K. \\ Phone: +44 (0)1223 (3)37114 \\ Email: cml49@cam.ac.uk
}

December 2014

\begin{abstract}
Using a holdings-based measure of active management termed the 'Segment Active Share', the paper documents that commercial real estate portfolios that are more active -i.e., have segment weights which are least like those of the index - have outperformed. Employing proprietary IPD data for 256 U.K. real estate funds over 2002-2011, we find that funds with high Segment Active Share on average outperformed the real estate market by $1.9 \%$ per year. These funds do not seem to take increased risk and their outperformance cannot be explained by fund size alone, though on average they are smaller funds.
\end{abstract}

This paper was sponsored by Aberdeen Asset Management PLC and was independently written by the authors. The authors thank Russell Chaplin, Ian Cullen and Chantelle Dickson for their helpful comments, but remain solely responsible for any errors. 
How Active is Your Real Estate Fund Manager?

\section{Introduction}

In structuring private real estate portfolios, which commercial real estate fund managers create most value for their investors; those which are able and willing to depart from the market index segment weights or those which tend to hold segment weights closer to the market index? Funds focusing on a subset of segments will tend to hold more concentrated portfolios relative to funds investing in most or all industry/geography segments. In doing so, these portfolios will differ more from the overall market such that they can be considered to be more actively managed.

Such increased concentration may be the outcome of improved managerial skill, conviction and opportunity. First, manager skill may be able to identify which segments offer superior value or that skill may involve an informational advantage in certain segments - leading to a focus on properties in those particular segments. Second, fund managers can only outperform the market if their fund is sufficiently distinct from the average, i.e. they need to have the courage of their convictions - which may include convictions on segment selection. These effects will be magnified where manager compensation is linked to outperformance (for example with performance incentives for beating a relative target or benchmark) encouraging the manager to take larger bets through concentration to cash in on the asymmetric reward structure. Third, a manager needs to have sufficient opportunity to implement their investment ability persistently, rather than be constrained by external or internal factors. External constraints may include a large portfolio size that implies that the fund has to invest in many properties across many segments. Internal constraints may include a risk-averse approach and a process that prioritizes relative performance, keeping the fund fairly close to the market weights - which includes properties across all segments.

On the other hand, less concentration across segments may have distinct advantages as well. First, most investment opportunities may be primarily within certain segments of the real estate market rather than across segments, i.e. broad segments may be generally fairly priced such that a more general skill is needed to identify individual properties with superior value that 
may exist in all segments. Second, investing across segments may lead to improved diversification and lower overall risk, especially in an illiquid asset class such as commercial real estate funds. Third, increased managerial opportunity may manifest itself in an unconstrained approach to invest wherever the properties with the best prospects are - which may be across many different segments in the commercial real estate industry. Fourth, portfolio managers may want to diversify their career risk through less concentrated portfolios. As a result, the association between the type of active management of real estate funds and fund performance seems ex ante unclear.

In this paper, we employ a large proprietary dataset from the Investment Property Databank (IPD) that includes detailed information on the holdings and performance of 256 private U.K. commercial real estate funds over 2002 to 2011 . This unique dataset allows us to consider the issues mentioned above and introduce several contributions to the literature studying the performance of the assets held by commercial real estate funds.

First, we construct a holdings-based measure of the degree of active management termed the Segment Active Share, which measures the difference in segment allocations of a fund relative to the average segment allocation in the market, as a proportion of the fund's total holdings. We separate all properties into ten segments according to their IPD classification (see Section 3). A high Segment Active Share indicates that the fund makes significant segment bets relative to the market, and a low Segment Active Share means that the fund has similar segment allocations relative to the market.

The Segment Active Share measure has its roots in the security-level Active Share measure introduced in Cremers and Petajisto (2009), who find that equity mutual funds whose holdings are most different from the holdings of their benchmarks - i.e., funds with the highest Active Share - outperform. ${ }^{1}$ Active Share is calculated as the proportion of the holdings of the fund that is different from the holdings of the benchmark, i.e. as the holdings or individual asset level. The finding that high Active Share managers persistently outperformed suggests that active management can benefit investors. However, Cremers and Petajisto (2009) also found

\footnotetext{
${ }^{1}$ Segment Active Share is further motivated by and closely related to the industry concentration measure introduced in Kacperczyk, Sialm and Zheng (2005). They find that equity mutual funds making less diversified allocations compared to the market in certain industries outperform.
} 
that many actively managed funds had relatively low Active Shares, or holdings that were quite similar to the holdings of the fund benchmarks, and that such 'closet index funds' persistently underperformed (mostly due to their costs). This underscores the importance of distinguishing between truly active funds and closet index funds.

This paper is, to the best of our knowledge, the first to apply the Active Share concept to securities other than equities. Ex ante, it is unclear whether real estate funds would give similar results as documented for equity funds, as the assets in real estate are substantially different from publicly traded equities: lumpy, fixed in location (so are more liable to local drivers of risk and return) and traded in private markets (and thus e.g. typically are held for much longer time periods). The commercial real estate market is the largest alternative asset class that a supermajority of pension funds invests in (and by far the largest asset class among alternative investments among pension funds, see e.g. Andonov et al., 2013), and thus a prime candidate for exploring whether active management in alternative investments works similar to active management in publicly traded equities. Another important difference from applying Active Share in equity markets is that the assets (i.e., properties) in the commercial real estate market are all unique, such that we have to adapt the security-level (which in the case of property would be the specific buildings) Active Share measure to the real estate portfolios, which we do by aggregating portfolio weights across properties in the same segment.

Because funds with high Segment Active Share depart more from the market index segment weights, they also tend to have higher tracking error volatility, i.e. a higher volatility of the return difference between the fund and its benchmark. Tracking error and Active Share are clearly distinct measures, however. The active bets - i.e., differences in fund weights relative to benchmark weights - can be well diversified or more concentrated, as explained in more detail in Cremers and Petajisto (2009). Funds with high Segment Active Share can thus have relatively low tracking error ('diversified segment selectors') or have high tracking error ('concentrated segment selectors'). Other funds could invest across all segments but do so by picking only few properties in each segment, resulting in low Segment Active Share but high tracking error ('focused segment selectors') - an effect emphasized by the heterogeneity of individual property assets. 
Cremers and Petajisto (2009) found that differences in Active Share mattered for performance, while differences in tracking error were unrelated to future fund performance. In this paper, we will focus on Segment Active Share, whose calculation has a significant advantage over tracking error. Segment Active Share is based on portfolio holdings, such that it can be measured ex ante at each snapshot in time without any estimation. Tracking error volatility is based on returns and has to be estimated, which for our time period of 40 quarterly returns can only be done ex post over the full time period, such that we cannot consider how tracking error relates to future fund performance as we can with Segment Active Share. Figure 1 presents a scatter plot each fund's average Segment Active Share together with their tracking error over the full period, for the sample of funds for which we have investment returns over the full 10year period. The figure indicates wide cross-sectional variation for both Segment Active Shares and tracking error. While positively correlated, the wide dispersion across these two dimensions shows that these two measures of active management are clearly distinct, and that funds whose segment weights differ significantly from the market often do not have high tracking error, i.e. are still well-diversified (diversified segment selectors).

In our sample, the average Segment Active Share score equals 47\%, with substantial variation across funds. At the beginning of each quarter, we sort funds into five quintile portfolios depending on their Segment Active Share score. Funds in the lowest quintile have an average Segment Active Share of only 30\%, such that these portfolios generally make few bets on specific segments. These funds contain on average 83 properties with an average fund size (as measured by the total capital value of its properties) of $£ 1.3$ billion. Funds in the highest quintile have an average Segment Active Share of $70 \%$, indicating that these funds are more concentrated and invest in only a subset of the 10 segments. The high Segment Active Share funds contain on average only 31 properties with an average fund size of $£ 200$ million.

Second, the database allows us to calculate quarterly total returns for each quintile. ${ }^{2}$ The capital returns are based on quarterly changes in the valuations of individual assets in each portfolio and the income is that receivable from the tenants in occupation. Using the Segment

\footnotetext{
${ }^{2}$ As noted below, our focus is on the real estate returns, not on the overall returns delivered to investors, which depend additionally on leverage and fund structure. Hereinafter we use "returns" to refer to the income returns and capital appreciation of the properties held in the funds.
} 
Active Share at the beginning of each quarter and sorting funds anew across quintiles every quarter shows how Segment Active Share can help predict future fund performance. We find that real estate funds in the highest Segment Active Share quintile significantly outperform, consistent with the evidence in Cremers and Petajisto (2009) for equity mutual funds.

The outperformance of the most active commercial real estate funds is economically significant. For example, an initial investment of $£ 100$ in the aggregate real estate market portfolio at the beginning of our ten-year time period (December 2001) would have been valued at $£ 186$ at the end of the period (December 2011), generating an average return of $6.4 \%$ per year. Such investment in the quintile portfolio with the lowest Segment Active Share funds exhibited very similar performance, with an end value of $£ 188$; implying an average annual return of $6.5 \%$. However, an initial $£ 100$ investment in the quintile portfolio with the highest Segment Active Share funds would have had a value of $£ 216$ after 10 years, i.e. an average return of $8.0 \%$ per year. The outperformance of funds which departed most from the segment weights of the markets is also statistically significant. We calculate the abnormal performance or alpha by regressing the quarterly returns of each portfolio on the average or market return. The quintile portfolio with highest Segment Active Share funds has an annualized alpha of $1.9 \%$ with a t-statistic of 4.77 , indicating that the outperformance is statistically robust.

Third, the higher returns of the funds with high Segment Active Share are not generated by increased risk. In fact, the more active funds tend to have slightly lower total volatility and beta than the average fund. For example, the quintile portfolio of funds with the $20 \%$ highest Segment Active Share has a beta (i.e., regression coefficient on the average market return) that is $6 \%$ lower than the average fund, showing that it has relatively lower exposure to systematic risk in the commercial real estate market. In addition, its total volatility of $8.0 \%$ per year is slightly lower than the overall market volatility of $8.4 \%$ per year, while their downside risk (or the maximum cumulative loss) is lower as well. We thus conclude that - notwithstanding their greater concentration in segments and generally considerably higher tracking error - funds with high Segment Active Shares are not more risky than the typical commercial real estate fund.

Fourth, the outperformance of the high Segment Active Share funds - which tend to hold fewer properties and are smaller - is not driven by their on average smaller fund size. We test this by sorting funds, each quarter, into five quintile portfolios based on fund size (i.e., the total 
capital value of its properties). As a group and without considering Segment Active Share, the $20 \%$ of smallest funds underperformed in our sample. As a result, differences in fund size cannot explain the outperformance of the funds with highest Segment Active Share. This also suggests that the outperformance of high Segment Active Share funds is more likely to come from funds outside the group of $20 \%$ of smallest funds.

Fifth, another potential concern may be that a policy of investing in funds with high Segment Active Share may not be practical. Typical investments in commercial real estate funds are held over longer periods, and the market in general is relatively illiquid compared to those of publicly traded equities and bonds. As a result, if Segment Active Shares greatly vary over time, following an investment strategy of consistently choosing funds with high Segment Active Shares may result in too high trading costs. However, we find that the Segment Active Share of most funds is fairly stable over our 10-year time period. To illustrate this and as a robustness check, we also sort funds into quintile portfolios based on their average Segment Active Share over the full 10-year time period, using only the subset of funds for which data is available for the full period. The quintile portfolio of funds with the highest average Segment Active Shares again outperforms, with an annualized alpha of $1.4 \%$ (t-statistic of 4.11 ).

We conclude that commercial real estate fund managers where the holdings looked least like the index created most value for their investors. Our basic result that commercial real estate funds with high Segment Active Share outperformed suggests that these managers on average have the skill to identify which segments offer superior value. Alternatively, these managers may achieve an informational advantage in certain segments. It may also be that such funds are unable to invest in particular segments because of their small fund size. For example, central London offices and large shopping centers may be beyond the reach of the smallest funds due to typically large lot sizes in these segments.

We further conclude that fund managers with high Segment Active Share indeed seem to have the courage of their convictions and be less constrained in implementing their investment strategy, as exemplified most strongly in the more limited number of different properties held in their portfolios. However, the portfolios of high Segment Active Share funds are as well-diversified as typical commercial real estate funds, and actually have slightly lower total volatility and downside risk than the overall market. 
The remainder of this paper is organized as follows. In Section 2 we briefly review some prior research on the performance of private real estate funds. Section 3 describes the data and the methodology. In section 4, we describe our main empirical results. Section 5 considers robustness checks and section 6 concludes.

\section{Prior Research}

By contrast to research on listed property companies and Real Estate Investment Trusts, research on private real estate funds is comparatively limited. In part, this results from problems in accessing robust data with sufficient time series. The growth of private real estate funds as an investment vehicle is a comparatively new phenomenon (see Alcock et al., 2013); data are proprietary and difficult to obtain and the returns delivered to investors result both from the performance of the real estate assets held and the capital structure of the fund.

Much of the early research on the performance of private real estate in portfolios has focused on property level diversification with, in the U.K., an emphasis on the benefits of sector (office, retail, industrial) and geographical diversification. ${ }^{3}$ This sector-region structure forms the basis of much of the benchmarking and performance measurement analysis in the U.K. property industry, despite some concerns about the coherence of individual property returns within each sector-geography segment (Callender et al., 2007; Devaney and Lizieri, 2005). Typically, fund performance is attributed to structure (the distribution of properties within segments) and property selection, reflecting the heterogeneity of individual buildings and their performance.

A literature exists on the performance of listed real estate stocks (for example, Brounen, Eichholtz and Ling, 2007) and of real estate mutual fund managers investing in REITs and other listed real estate (for example Hartzell, Mühlhofer and Titman, 2009) which, echoing more general findings from equity markets, shows little evidence of significant outperformance or persistence thereof. There is less evidence for private real estate funds. Hahn, Geltner and Gerado-Lietz (2005) examine real estate opportunity funds and, adapting non-parametric tests employed by Brown and Goetzmann (1995), test whether more successful fund managers repeat their success with subsequent funds. They find some weak evidence of persistence of

\footnotetext{
${ }^{3}$ For a recent review, see Lee and Devaney (2007) and the references therein.
} 
underperformance, but little evidence that being a "winner" fund predicts subsequent success with higher management fees largely eliminating any potential gains.

Within U.K. markets, Bond and Mitchell (2010) use Investment Property Databank (IPD) data to test whether there is evidence of persistence in superior performance. They calculate an alpha measure based on a regression of fund returns on market segment returns weighted by portfolio holdings of those segments, and then sort funds into quantiles. There is, at best, weak evidence that the top decile performing funds have a higher probability of being in the upper half of the distribution in the next period, but any such persistence quickly dissipates and alphas converge to the industry average. Fuerst and Marcato (2009) perform a style analysis for a dataset of hypothetical portfolios constructed from individual asset returns. They find that portfolio structure (in particular lease structure) has some significance in predicting the probability of positive alpha. Alcock, Baum, Colley and Steiner (2013) examine fund returns (including capital structure effects) in a fixed effect panel framework to test whether managers can time leverage decisions. Their market model suggests persistent negative alpha (attributed to the impact of management fees) and no evidence of leverage timing ability, with increased risk associated with underperformance in down markets but not contributing significant gains in rising markets.

The research here focuses on the performance of actual properties within real estate portfolios held by professional investors. We extend the literature by examining the results of portfolio structure decisions taken by managers. Given large lot sizes and comparatively small numbers of properties held within each fund, returns will also be influenced by property selection. However, our method focuses on the decision to focus investment activity or spread it more widely: property selection skills applied within a segment versus across segments.

\section{Data and methodology}

Our proprietary data are from the UK database of the Investment Property Databank (IPD). The IPD UK database contains asset-specific details for about 300 funds that are valued on a quarterly basis. Over $90 \%$ of these funds have performances data available for at least three years. All statistical analyses conducted using these data that involved fund-level information were conducted at IPD by its research team overseen by lan Cullen, e.g. producing the quarterly 
data on portfolio characteristics and returns that were used to produce all the results in this paper. This work was directed by the authors.

IPD conducted a detailed, fund-by-fund, analysis to identify the sample appropriate to our purpose by excluding funds not relevant to our analysis. We excluded those specialist funds that targeted only specific sectors (e.g. office only or shopping centre only funds) or geographical areas (e.g. City of London funds) and 'Traditional Estate' portfolios that are based on inherited assets with very little portfolio turnover. After such screening, the sample consists of 256 commercial real estate funds with general diversified real estate mandates for which quarterly returns are available over at least part of the ten year period from the beginning of 2002 to the end of 2011. The sample covers a range of fund types including, comingled and separate own-account funds, open-ended and closed-ended structures and finite-life and infinite funds.

Our data represent a significant proportion of the total UK commercial real estate market. The total capital value of the funds in our sample at the end of 2011 is $£ 93.16$ billion, which is about $80 \%$ of the total capital value of the aggregate IPD quarterly index (see IPD, 2012). This further amounts to about $28 \%$ of the overall professional grade commercial real estate market in the UK, using the estimate of the total direct ownership of the total UK investment commercial property market from the Property Industry Alliance (2012).

Our database is essentially free of survivorship-bias. All funds included are professionally managed, mostly by life insurance companies, pension funds or big financial institutions. As such, failure rates are extremely low, including in the recent financial crisis. In our data, about $0.5 \%$ of funds exit the database per quarter, and those exits are fairly evenly distributed across time and across Segment Active Share groups. The exit rate per quarter after July 2007 equals $0.54 \%$, so almost identical to the average exit rate of $0.5 \%$. The reason funds drop out of our sample is because they reach the end of life (and are dissolved) or because they are sold in portfolio transactions (rather than failed). Over the course of the analysis, new funds join the IPD database on a steady basis ${ }^{4}$. Fewer funds arrive during the financial crisis, but the number of

\footnotetext{
${ }^{4}$ New fund arrivals do not fundamentally shift the benchmark over the analysis period. Examining the full IPD databank, the largest change between 2002-2011 is a shift out of holdings of City of London offices (which fall from around $11 \%$ to just below $6 \%$ ) but this is part of a secular trend as the City is increasingly dominated by non-
} 
funds in the analysis in December 2011, 171, is only 15 fewer than the 185 at the peak in September 2007. The lowest number of funds available in any quarter is 154 .

IPD estimated the total investment returns for each property portfolio, by aggregating individual property level returns and incorporating fund management costs, cash balances and other costs. IPD calculates quarterly investment returns based on net income received and quarterly changes in the individual property values, adjusted for management and maintenance costs, capital expenditure, fees and other transaction costs ${ }^{5}$. The property values are based on arms-length professional valuations and, hence, are subject to appraisal smoothing effects. All properties included in the quarterly index are valued each quarter and thus there is no "stale appraisal" problem as is apparent for NCREIF returns in the US where properties are included whether or not an appraisal has recently taken place. Nonetheless, illiquidity and infrequent trading mean that valuations will tend to lag the pricing effects of shocks that would be observed much earlier in more liquid markets. ${ }^{6}$ However, since we are comparing performance across funds calculated on the same basis within the real estate sector, this should not materially affect the results reported here. The valuation-based returns are as reported to clients and performance monitoring services, and form the basis of performance fees for fund managers.

Each property is classified as falling into one of ten "PAS" (Portfolio Analysis Service) segments which reflect a classification of U.K. commercial real estate by sector of activity and geography. ${ }^{7}$ The PAS segments form the basis of IPD's benchmarking service and, hence, have a significance for professional real estate investors in the UK. For many fund managers, performance is evaluated in relation to the benchmark IPD index with performance bonuses tied to "beating the index" while attribution analysis using the PAS segments is used to explain the components of out- or under-performance. The segments used in the analysis are:

\footnotetext{
UK investors. The fall also reflects the relatively sharper decline in capital values in the City office market in the financial crisis.

${ }^{5}$ For more details of IPD's return methods see the IPD Index Guide, which is available at www.ipd.com/indexguide/.

${ }^{6}$ Devaney and Martinez Diaz (2011) produce evidence that suggests a repeat sales, transaction based index does not seriously lag the IPD appraisal based index although it exhibits substantially greater volatility.

7 Properties in the 'other' segment were excluded and the remaining portfolio weights were rescaled, as the assets in this property are too diverse to be comparable across funds. However, these assets constitute a small proportion of typical portfolios such that their inclusion would be unlikely to change any inference.
} 
1. Standard Retail South East

2. Standard Retail Rest UK

3. Shopping Centre

4. Retail Warehouse

5. Office City

6. Office West End \& Mid Town

7. Office Rest South East

8. Office Rest UK

9. Industrial South Eastern

10. Industrial Rest UK

For each portfolio, IPD aggregates up the portfolio weights of properties within each of these segments based on the capital value of each property at the start of each period, resulting in the portfolio segment weights. These weights at the segment level are then compared to the average industry segment weights for all properties whose returns are reported in the IPD U.K. Quarterly Index. This aggregation of individual properties to portfolio weights at the segment level is necessary in order to construct a holdings-based measure of the degree of active management. As the assets - the individual commercial real estate buildings - are all unique, we have to adapt the security-level Active Share measure introduced in Cremers and Petajisto (2009). Active Share is the proportion of fund holdings that is different from the holdings in the fund benchmark.

We label our adapted measure the 'Segment Active Share,' as it measures how different fund allocations across segments are from the allocations in the overall market, as a proportion of the fund's total holdings. A high Segment Active Share indicates that the fund makes significant segment allocations away from the market weights, and a low Segment Active Share means that the fund has similar segment allocations relative to the average in the benchmark index. The market weights are those reported in IPD's quarterly market index and are determined by summing the capital values of all the properties in each segment and then dividing by the aggregate capital value of properties included in the index. Conducting the same exercise solely using the properties held in the funds analyzed produces weightings that are nearly identical to the market weights of the full index. 
Specifically, the Segment Active Share of each portfolio is calculated as follows:

$$
\text { Segment Active Share }=\frac{1}{2} \sum_{k=1}^{10}\left|w_{f u n d, k}-w_{\text {market }, k}\right| \text {, }
$$

where $w_{\text {fund, } k}$ is the weight of segment ' $\mathrm{k}$ ' of the fund, and $w_{\text {market, } k}$ is the weight of segment ' $\mathrm{k}$ ' of the overall market. The absolute values of the differences in segment weights are summed up across the industry segments, and this is divided by 2 . If a fund does not go short or use leverage (which is the case by definition here, as IPD reported fund performance and holdings are for the underlying assets and do not reflect any fund level leverage), the Segment Active Share will be between $0 \%$ (identical segment weights to the market) and close to $100 \%$ (almost no overlap in segment weights). Given the relatively small number of assets held in portfolios and heterogeneity in capital values, it is unlikely that all but the very largest portfolios could have a Segment Active Share close to zero.

In our sample, the average Segment Active Share (across funds and years) equals 47\%, with substantial variation across funds. That means that for a typical fund, about half of its portfolio is invested in segments in the same proportion as the overall market. The crosssectional average Segment Active Share is quite stable over time.

Exhibit 1 provides more detail of the wide range of Segment Active Shares, together with how Segment Active Share is related to tracking error. For the sample of funds for which we have investment returns over the full 10-year period, we calculate the average Segment Active Share as well as its annualized tracking error relative to the market portfolio over this period. Specifically, the tracking error (or tracking error volatility) of each fund equals the standard deviation of the difference of its return with the market portfolio returns over the 40 quarterly returns. The figure indicates that both Segment Active Shares and tracking error display wide cross-sectional variation. While Segment Active Share and tracking error are positively correlated, given most ranges of Segment Active Share we find funds with widely varying tracking error, and vice versa. That suggests that funds whose segment weights differ significantly from the market can still be well-diversified (i.e., diversified segment selectors). On the other hand, some funds with low Segment Active Shares exhibited very large tracking errors, 
indicating the potential of significant dispersion of investment returns among buildings within (rather than just across) particular segments.

\section{Exhibit 1. Scatter Plot of Segment Active Share and Tracking Error}

For all funds for which the investment performance is available over the full 10-year period, we plot the average Segment Active Share (on the $\mathrm{Y}$-axis) over this period together with the annualized tracking error (or tracking error volatility, on the X-axis). The tracking error is calculated as the standard deviation of the difference of the 40 quarterly returns over the period between the fund and the market portfolio. The red lines indicate the median values for the average Segment Active Share (horizontal) and for the tracking error (vertical).

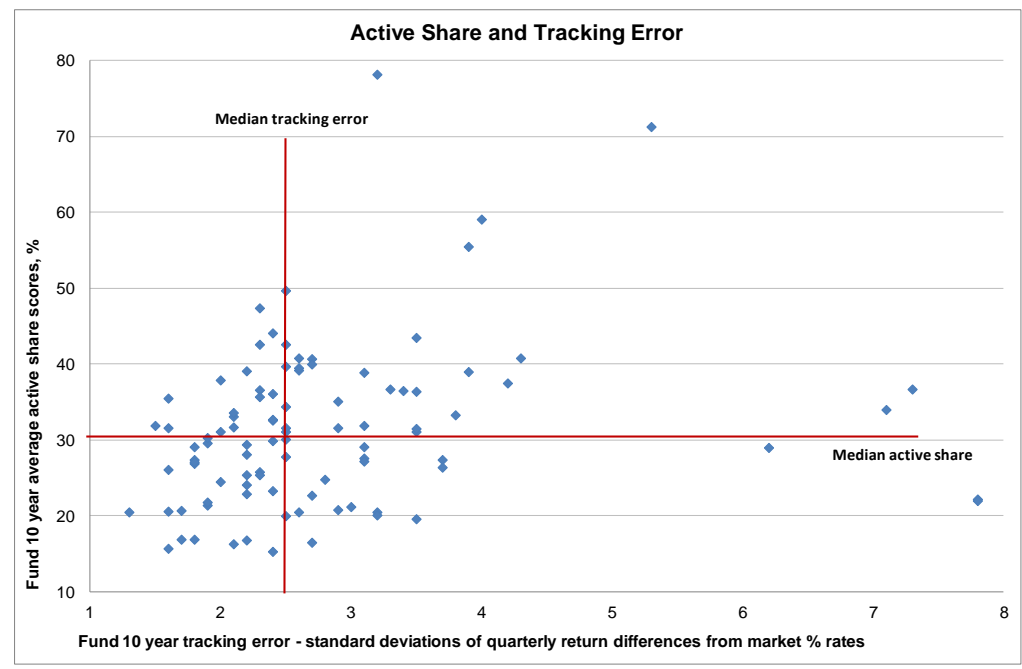

Having calculated the Segment Active Share score of each fund every quarter, we then examine the risk and return performance of funds, dividing the funds into quintile groups according to their scores. We examine the market-adjusted performance of each group to test whether funds in the highest Segment Active Share quintile demonstrate superior (or worse) performance compared to funds in lower quintiles. We test alternative specifications and conduct robustness tests relating to size of funds to eliminate alternative explanations of performance differentials.

\section{Main Empirical Results}

Our main results are conducted using quintile portfolios based on the quarterly Segment Active Shares of all funds with available data in the sample in that given quarter. From the total of 256 funds included in our sample during at least some quarter in our 10-year period, on average about 210 funds are included in the sort that is done each quarter. Every quarter, all funds with available data are sorted into five quintile portfolios according to their Segment 
Active Share at the beginning of the period. That means that over time, the same fund could be allocated to a different quintile portfolio if its Segment Active Share changes considerably (the overall distribution of Segment Active Shares remains quite stable of time). For each portfolio, every quarter the equally-weighted average investment return is calculated of all funds in the portfolio, together with the averages of several other fund characteristics, such as the number of different properties and the size of the fund (calculated as the total capital value of the properties owned by the fund).

Exhibit 2 presents basic descriptive statistics of the five quintile Segment Active Share portfolios and the overall market. The market portfolio is calculated as the value-weighted average across all funds with available quarterly data, i.e., weighted by the total value of the properties in each fund. For each portfolio, we report the mean, standard deviation, minimum and maximum of the 40 quarterly returns in its time series of 2002:Q1 to 2011:Q4. For the five quintile portfolios, we further report the average Segment Active Share, the average number of different properties in the portfolio as well as the average capital value of these properties.

We document considerable cross-sectional variation in the extent to which different real estate funds choose segments weights differently from the overall market allocations. We highlight such differences by comparing the funds in the lowest versus the highest Segment Active Share quintiles. Starting with funds in the lowest Segment Active Share quintile, these have on average a Segment Active Share of only $30 \%$. Therefore, these portfolios generally make few bets on specific segments. On average, these low Segment Active Share funds contain 83 properties with an average capital value of $£ 1.3$ billion. This indicates that on average the funds in the lowest quintile Segment Active Share are larger and able to access more segments such as central London offices and large shopping centers. By contrast, the real estate funds in the highest quintile have an average Segment Active Share of $70 \%$. This indicates that these funds are significantly more concentrated than the low Segment Active Share funds and typically invest in only a subset of the segments. Funds in the high Segment Active Share quintile contain on average only 31 properties with an average capital value of 200 million pounds. Such funds would on average be unable to participate in any meaningful way in the central London office market or the larger UK shopping centers.

Exhibit 2. Descriptive Statistics of the Segment Active Share Quintile Portfolios 
The table presents basic descriptive statistics of the five Segment Active Share quintile portfolios and the overall market. Every quarter, all funds with available data are sorted into five quintile portfolios according to their Segment Active Share at the beginning of the period. For each portfolio, every quarter the average investment return is calculated of all funds in the portfolio, together with the averages of each fund's Segment Active Share, the number of different properties and the total (i.e., sum of the) capital value of all the properties. The market portfolio is calculated as the average across all funds with available data, weighted by the total value of the properties in each fund. For each portfolio, we report the mean, standard deviation, the tracking error (volatility) relative to the market portfolio, minimum and maximum of the 40 quarterly returns in its time series of 2002:Q1 to 2011:Q4, plus the time series mean of the average Segment Active Share, the average number of different properties in the portfolio as well as the average capital value of these properties.

\begin{tabular}{|c|c|c|c|c|c|c|c|c|}
\hline & $\begin{array}{l}\text { Mean } \\
\text { Segment } \\
\text { Active } \\
\text { Share }\end{array}$ & $\begin{array}{c}\text { Mean } \\
\text { Quarterly } \\
\text { Return }\end{array}$ & $\begin{array}{c}\text { Std. Dev. Of } \\
\text { Quarterly } \\
\text { Return }\end{array}$ & $\begin{array}{c}\text { Quarterl } \\
\text { y } \\
\text { Portfolio } \\
\text { Tracking } \\
\text { Error }\end{array}$ & $\begin{array}{c}\text { Minimum } \\
\text { Quarterly } \\
\text { Return }\end{array}$ & $\begin{array}{c}\text { Maximu } \\
\text { m } \\
\text { Quarterly } \\
\text { Return }\end{array}$ & $\begin{array}{c}\text { Mean } \\
\text { Number of } \\
\text { Properties }\end{array}$ & $\begin{array}{c}\text { Mean } \\
\text { Capital } \\
\text { Value } \\
\text { (millions) }\end{array}$ \\
\hline Market Portfolio & $47.76 \%$ & $1.65 \%$ & $4.22 \%$ & & $-13.33 \%$ & $9.35 \%$ & 61 & $£ 7,45$ \\
\hline \multicolumn{9}{|c|}{ Q1 - lowest Segment } \\
\hline Active Share & $29.83 \%$ & $1.68 \%$ & $4.27 \%$ & $0.22 \%$ & $-13.26 \%$ & $9.50 \%$ & 83 & $£ 1,249$ \\
\hline Q2 & $39.20 \%$ & $1.58 \%$ & $4.19 \%$ & $0.32 \%$ & $-13.05 \%$ & $9.15 \%$ & 57 & $£ 546$ \\
\hline Q3 & $46.88 \%$ & $1.46 \%$ & $4.35 \%$ & $0.47 \%$ & $-14.78 \%$ & $9.52 \%$ & 49 & $£ 445$ \\
\hline Q4 & $53.07 \%$ & $1.68 \%$ & $4.20 \%$ & $0.48 \%$ & $-13.24 \%$ & $8.73 \%$ & 41 & $£ 348$ \\
\hline \multicolumn{9}{|c|}{ Q5 - highest Segment } \\
\hline Active Share & $69.92 \%$ & $2.03 \%$ & $4.02 \%$ & $0.62 \%$ & $-11.95 \%$ & $10.08 \%$ & 31 & $£ 197$ \\
\hline
\end{tabular}

Real estate funds in the highest Segment Active Share quintile significantly outperform the average real estate fund, whereas funds in the lowest Segment Active Share quintile have returns that are basically the same as those of the overall market portfolio. Specifically, the mean quarterly return of the highest Segment Active Share quintile equals $2.03 \%$, versus $1.65 \%$ for the market portfolio and $1.68 \%$ for the lowest Segment Active Share quintile.

Another way to illustrate the economically significant outperformance of the most active commercial real estate funds is to consider the growth in value of an initial investment of $£ 100$ at the beginning of our ten-year time period as presented in Exhibit 3 . This $£ 100$ initial investment in the lowest Segment Active Share portfolio would have been valued at $f 188$ at the end of the period, implying an (geometric) average annual return of $6.5 \%$. However, an initial $£ 100$ investment in the quintile portfolio with the highest Segment Active Share funds would have had a value of $£ 216$ after 10 years, i.e. an average return of $8.0 \%$ per year. 
Exhibit 3. Growth in value of initial investment of $£ 100$ in the Segment Active Share Quintile Portfolios

The figure plots the cumulative total gross return of an initial investment of $£ 100$ in the five quintile Segment Active Share portfolios over the next 10 years. Every quarter, all funds with available data are sorted into five quintile portfolios according to their Segment Active Share at the beginning of the quarter. For each portfolio, every quarter the average investment return is calculated of all funds in the portfolio, and then the cumulative total gross return of that portfolio is tracked over time.

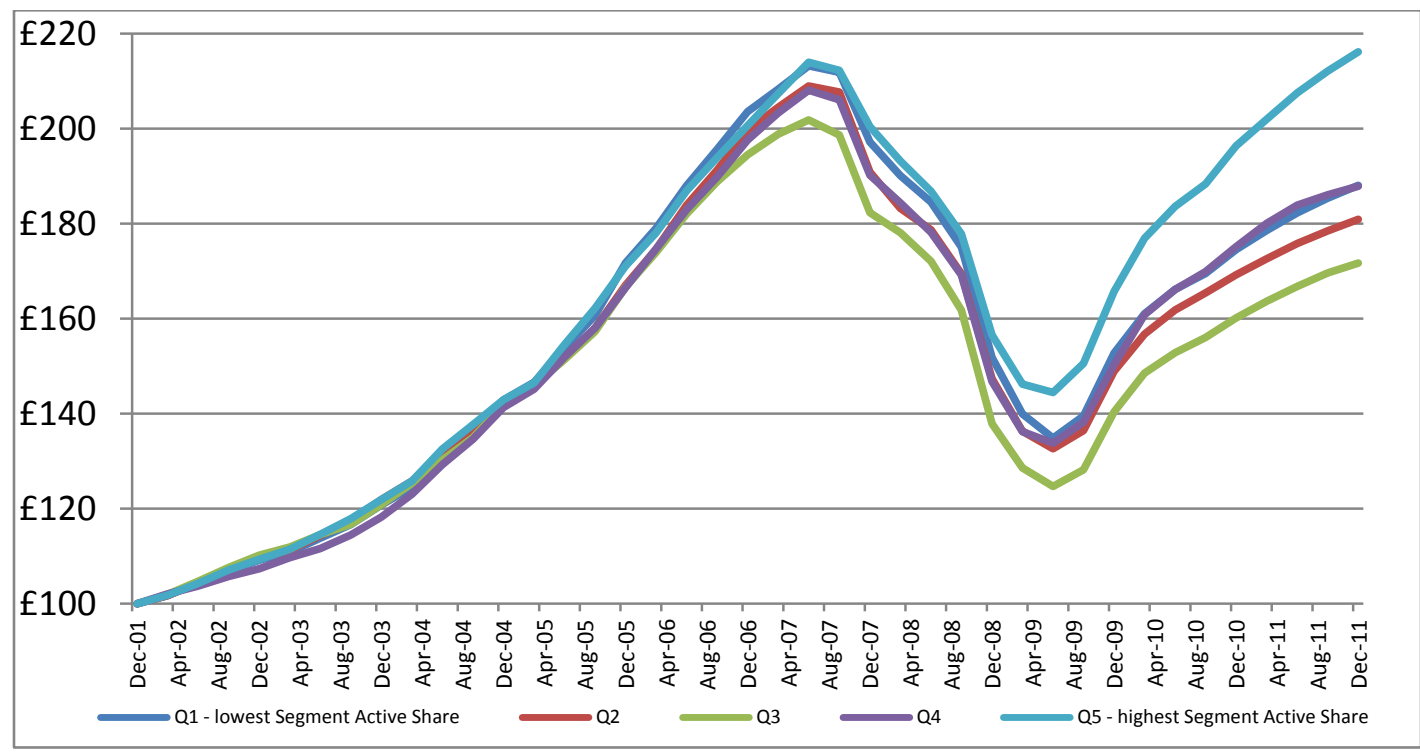

The outperformance of the more active real estate portfolios is also statistically significant. We calculate the abnormal performance or 'alpha' by regressing the 40 quarterly returns of each Segment Active Share quintile portfolio on a constant and the return of the real estate market portfolio. The coefficient on the market return is termed 'Beta' and the coefficient on the constant is termed 'Alpha' and can be considered the abnormal return relative to the portfolios exposure to the overall real estate market. The regression results are reported in Exhibit 4.

\section{Exhibit 4. Abnormal Performance of the Segment Active Share Quintile Portfolios}

The table reports the abnormal performance of five Segment Active Share quintile portfolios (in columns $1-5$ ), as well as the results for a long-short portfolio ('Q5 - Q1', see column 6) that buys the highest Segment Active Share portfolio (Q5) and sells the lowest Segment Active Share portfolio (Q1). Every quarter, all funds with available data are sorted into five quintile portfolios according to their Segment Active Share at the beginning of the period. For each portfolio, every quarter the average investment return is calculated of all funds in the portfolio. These portfolio returns are then regressed on a constant and the returns of the real estate market portfolio. The coefficient on the market return is termed 'Beta' and the coefficient on the constant is termed 'Alpha' and can be considered the abnormal return relative to the portfolios exposure to the overall real estate market. $\mathrm{N}$ denotes the number of quarterly returns used in the regression and R-sq is the percentage of total return variation captured. T-statistics based on heteroskedasticity-robust (i.e., White) standard errors are given between parentheses. ${ }^{* * *}$ and ${ }^{* *}$ denote statistical significance at the $1 \%$ and $5 \%$ margin, respectively. 
(1)

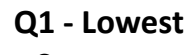

Segment

Active Share

\begin{tabular}{lcccccc}
\hline Beta & $1.011^{* * *}$ & $0.990^{* * *}$ & $1.024^{* * *}$ & $0.988^{* * *}$ & $0.943^{* * *}$ & $-0.0677^{* * *}$ \\
& $(88.98)$ & $(70.32)$ & $(35.40)$ & $(59.42)$ & $(41.01)$ & $(-2.78)$ \\
& & & & & & \\
Alpha & 0.0152 & -0.0516 & $-0.233^{* *}$ & 0.0469 & $0.471^{* * *}$ & $0.455^{* * *}$ \\
& $(0.34)$ & $(-0.86)$ & $(-2.17)$ & $(0.63)$ & $(4.77)$ & $(4.21)$ \\
& & & & & & 40 \\
$\mathrm{~N}$ & 40 & 40 & 40 & 40 & 0.979 & 0.158 \\
R-sq & 0.997 & 0.994 & 0.989 & 0.987 & 0.979 \\
\hline
\end{tabular}

The quintile portfolio with highest Segment Active Share - see column 5 - has an annualized alpha of $1.9 \%(=4 \times 0.471)$ with a t-statistic of 4.77 , indicating that its outperformance is statistically significant. In contrast, none of the other Segment Active Share quintile portfolios exhibit positive abnormal performance. Column 6 indicates that the difference in performance between the highest and lowest Segment Active Share quintile portfolios is both economically and statistically significant at $1.8 \%$ per year.

Curiously, the portfolio of funds with median Segment Active Share (Q3, see column 3) has a statistically significant negative alpha. A potential explanation for this may be that some specialization is useful, and funds with median Segment Active Share are not specializing in particular segments (otherwise they would have high Segment Active Share) nor do they seem to be focusing on bottom-up property selection across all segments (in which case they would have low Segment Active Share).

The results in Exhibits 2 and 4 further show that the higher returns of the highest Segment Active Share funds are not generated because those funds are more risky. Column 3 of Exhibit 2 shows that the quintile portfolio with the most active funds has slightly lower total return volatility than the other quintile portfolios - its total volatility equals $8.0 \%$ per year, which is a bit lower than the overall market volatility of $8.4 \%$ per year. Exhibit 4 shows that the real estate funds with the highest Segment Active Share also had relatively lower exposure to systematic risk in the commercial real estate market, which can be measured by the beta of each fund. For example, the quintile portfolio of funds with the $20 \%$ highest Segment Active Share has 
a beta (i.e., regression coefficient on the market return) that is $6 \%$ lower than the average beta, and column 6 shows that this difference is also strongly statistically significant.

Another useful risk measure capturing down-side risk is the maximum cumulative loss, i.e. the most negative 'peak to trough' return over the sample. For all real estate portfolios that we considered in this paper, the largest cumulative loss was sustained in the 2-year period from June 2007 to June 2009. The overall real estate market had a cumulative loss of $-36 \%$ over this period. The maximum cumulative loss of the first four Segment Active Share quintile portfolios is likewise in the range of $-38 \%$ to $-36 \%$. However, the quintile portfolio of funds with the highest Segment Active Share had a lower cumulative loss over that period of $-32 \%$. We thus conclude that - notwithstanding their much lower number of properties than typical and higher tracking error volatility - funds with high Segment Active Share are at least as well diversified as the typical commercial real estate fund, having been slightly less risky than the other funds in our sample.

\section{Robustness Checks}

In this subsection, we consider two potential concerns with our main results. The first concern is that funds whose holdings are more concentrated in a few segments typically also have many fewer holdings than average. In particular, we noted above that the funds in the quintile with highest Segment Active Share hold on average 31 different properties, compared to an average of 44 . As a result, it is possible that their outperformance is not due to any particular skill in selecting segments or any information advantage in particular segments, but could rather potentially be due to diseconomies of scale in commercial real estate or other factors related to portfolio size.

The second concern is that our main results (as described in the previous subsection) allow individual funds to move across different Segment Active Share quintile portfolios. This is because we sort all funds with available data anew each quarter, such that if a fund's Segment Active Share significantly changes over time its assorted quintile portfolio will likewise change. This could potentially render our exercise impractical, as the general nature of investing in commercial real estate funds renders frequent trading costly and impractical. Typically, 
investments in commercial real estate funds are held over longer periods, and the market is relatively illiquid compared to the markets of publicly traded equities and bonds.

We start with considering the first concern by sorting, each quarter, all funds with available data into different fund size quintile portfolios according to the sum of the capital values of the different properties owned by the fund. Otherwise, the size quintile portfolios are constructed in the same way as the Segment Active Share quintile portfolios. Exhibit 5 reports the descriptive statistics of the size quintile portfolios. Consistent with the descriptive statistics of the Segment Active Share quintile portfolios in Exhibit 2, column 1 of Exhibit 5 shows that large real estate funds tend to be considerably less active. ${ }^{8}$

\section{Exhibit 5. Descriptive Statistics of the Size Quintile Portfolios}

The table presents basic descriptive statistics of the five size quintile portfolios and the overall market. Every quarter, all funds with available data are sorted into five fund size quintile portfolios according to the total capital value of all of the properties contained in the fund as measured at the beginning of the period. See Exhibit 2 for a further description.

\begin{tabular}{|c|c|c|c|c|c|c|}
\hline $\begin{array}{c}\text { Mean } \\
\text { Segment } \\
\text { Active Share }\end{array}$ & $\begin{array}{l}\text { Mean } \\
\text { Quarterly } \\
\text { Return }\end{array}$ & $\begin{array}{c}\text { Std. Dev. Of } \\
\text { Quarterly } \\
\text { Return }\end{array}$ & $\begin{array}{c}\text { Minimum } \\
\text { Quarterly } \\
\text { Return }\end{array}$ & $\begin{array}{c}\text { Maximum } \\
\text { Quarterly } \\
\text { Return }\end{array}$ & $\begin{array}{c}\text { Mean } \\
\text { Number of } \\
\text { Properties }\end{array}$ & $\begin{array}{c}\text { Mean Capital } \\
\text { Value } \\
\text { (millions) }\end{array}$ \\
\hline
\end{tabular}

\begin{tabular}{cccccccc} 
Q1 - Smallest Size & $48.23 \%$ & $0.88 \%$ & $5.58 \%$ & $-18.88 \%$ & $11.96 \%$ & 15 & $£ 43$ \\
Q2 & $41.26 \%$ & $1.37 \%$ & $5.07 \%$ & $-17.14 \%$ & $11.49 \%$ & 24 & $£ 115$ \\
Q3 & $37.30 \%$ & $1.73 \%$ & $4.63 \%$ & $-15.32 \%$ & $11.26 \%$ & 33 & $£ 223$ \\
Q4 & $31.91 \%$ & $1.73 \%$ & $4.60 \%$ & $-15.61 \%$ & $9.61 \%$ & 49 & $£ 469$ \\
Q5 - Large Size & $24.90 \%$ & $1.68 \%$ & $4.31 \%$ & $-13.34 \%$ & $9.51 \%$ & 102 & $£ 1,790$ \\
\hline
\end{tabular}

However, the performance results indicate that small funds have performed poorly over our time period (whereas funds in the highest Segment Active Share quintile outperformed, despite having fewer properties and a lower market capitalization on average than other funds). While outside the scope of this paper, the underperformance of small funds suggests potentially positive economies of scale in managing real estate portfolios. For our more direct purpose of checking robustness, it means that our result that active funds outperform is very unlikely to be explained by any fund size effect.

\footnotetext{
${ }^{8}$ Larger funds by market capitalization are able to access certain markets that are out of reach for smaller funds such as the prime central London office market or regional shopping centre market and may tend to retain such assets. However, this does not seem to be associated with a specialisation in those areas - perhaps due to fund limitations on exposure to individual assets or segments. We would remind readers, though, that sector specialist funds are excluded from this analysis.
} 
Next, we regress the 40 quarterly returns of each size quintile portfolio on a constant and the return of the real estate market portfolio, generating an estimate of its alpha (i.e., the abnormal return that is not explained by exposure to the overall real estate market) and beta. These results are reported in Exhibit 6. Columns 1 and 2 of Exhibit 6 confirm that small real estate portfolios have performed poorly over our time period. The smallest size quintile portfolio (Q1) has an annualized alpha of $-5.0 \%$ (with a t-statistic of 4.79 - see column 1 ), while the second-to-smallest size quintile portfolio (Q2) has an alpha equal to $-2.2 \%$ per year (with a tstatistic of 2.31). However, the portfolios with large fund sizes did not outperform, as all of their alpha estimates are close to zero and statistically insignificant.

\section{Exhibit 6. Abnormal Performance of the Size Quintile Portfolios}

The table reports the abnormal performance of five Size quintile portfolios (in columns $1-5$ ), as well as the results for a long-short portfolio ('Q5 - Q1', see column 6) that buys the largest size portfolio (Q5) and sells the smallest size portfolio (Q1). Every quarter, all funds with available data are sorted into five fund size quintile portfolios according to the total capital value of all of the properties contained in the fund as measured at the beginning of the period. See Exhibit 4 for further explanation.

(1)

\section{Q1 - Smallest} Size
(2)

Q2

$1.167^{* * *}$

(18.77)

(18.64)

Alpha

$-1.257^{* * *}$

$(-4.79)$
$-0.556 * *$

$(-2.31)$
(3)

Q3
(4)

Q4
(5)

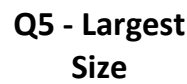

(6)

Q5 - Q1

\begin{tabular}{lcccccc} 
Beta & $1.294^{* * *}$ & $1.167^{* * *}$ & $1.092^{* * *}$ & $1.083^{* * *}$ & $1.019 * * *$ & $-0.275^{* * *}$ \\
& $(18.64)$ & $(18.77)$ & $(40.35)$ & $(34.82)$ & $(133.43)$ & $(3.98)$ \\
& & & & & & \\
Alpha & $-1.257^{* * *}$ & $-0.556^{* *}$ & -0.0675 & -0.0547 & -0.00125 & $1.256^{* * *}$ \\
& $(-4.79)$ & $(-2.31)$ & $(-0.83)$ & $(-0.52)$ & $(-0.04)$ & $(-4.84)$ \\
& & & & & 40 & 40 \\
N & 40 & 40 & 40 & 40 & 40 & 0.504 \\
R-sq & 0.958 & 0.945 & 0.990 & 0.989 & 0.998 & 0.59 \\
\hline
\end{tabular}

If we add both of those extreme-size quintile portfolios as additional factors - next to the market return - to our regression as run for Exhibit 4, we find unsurprisingly that the returns of the highest Segment Active Share quintile portfolio have a negative exposure to the smallest size quintile portfolio and a positive exposure to the largest size quintile portfolio. In this specification, the estimated abnormal return of the highest Segment Active Share quintile portfolio increases to $2.3 \%$ per year (with a t-statistic of 3.57 - results are not tabulated but are available upon request). Therefore, incorporating the underperformance of the smaller funds in 
our time period only strengthens the evidence that the most active real estate funds outperformed.

That leaves the second potential concern, namely that policy of investing in high Segment Active Share funds may not be practical because Segment Active Shares change too much over time, thus rendering such policy overly costly. We find however that the Segment Active Share score is fairly stable for most funds over our 10 -year time period. We illustrate this by sorting all funds into yet another set of five quintile portfolios, now based on their average Segment Active Share over the full 10-year time period, using only funds for which data is available for the full period - which leaves a sample of 96 real estate funds. Their descriptive statistics can be found in Exhibit 7 and the results of their return regressions to estimate alphas and betas are presented in Exhibit 8.

\section{Exhibit 7. Descriptive Statistics of the 10-Year Average Segment Active Share Quintile Portfolios}

The table presents basic descriptive statistics of the five quintile portfolios sorted by their 10-year average Segment Active Share, using only funds with available data over the full 10 -year period. See Exhbit 2 for further description.

\begin{tabular}{|c|c|c|c|c|c|c|}
\hline $\begin{array}{l}\text { Mean } \\
\text { Segment } \\
\text { Active } \\
\text { Share }\end{array}$ & $\begin{array}{c}\text { Mean } \\
\text { Quarterly } \\
\text { Return }\end{array}$ & $\begin{array}{c}\text { Std. Dev. } \\
\text { Of } \\
\text { Quarterly } \\
\text { Return }\end{array}$ & $\begin{array}{c}\text { Minimum } \\
\text { Quarterly } \\
\text { Return }\end{array}$ & $\begin{array}{c}\text { Maximum } \\
\text { Quarterly } \\
\text { Return }\end{array}$ & $\begin{array}{c}\text { Mean } \\
\text { Number } \\
\text { of } \\
\text { Properties }\end{array}$ & $\begin{array}{l}\text { Mean } \\
\text { Capital } \\
\text { Value } \\
\text { (millions) }\end{array}$ \\
\hline
\end{tabular}

\begin{tabular}{|c|c|c|c|c|c|c|c|}
\hline $\begin{array}{c}\text { Q1 - Lowest 10-Year Average } \\
\text { Segment Active Share }\end{array}$ & $29.13 \%$ & $1.73 \%$ & $4.26 \%$ & $-13.35 \%$ & $9.45 \%$ & 95 & $f 1,529$ \\
\hline Q2 & $35.45 \%$ & $1.54 \%$ & $4.59 \%$ & $-14.85 \%$ & $10.43 \%$ & 56 & $f 757$ \\
\hline Q3 & $43.25 \%$ & $1.49 \%$ & $4.05 \%$ & $-12.95 \%$ & $8.32 \%$ & 49 & $£ 378$ \\
\hline Q4 & $51.70 \%$ & $1.76 \%$ & $4.21 \%$ & $-13.98 \%$ & $9.29 \%$ & 41 & f218 \\
\hline $\begin{array}{c}\text { Q5 - Highest } 10 \text {-Year Average } \\
\text { Segment Active Share }\end{array}$ & $59.11 \%$ & $1.86 \%$ & $3.88 \%$ & $-11.38 \%$ & $9.16 \%$ & 36 & $£ 187$ \\
\hline
\end{tabular}

These results indicate that funds with the highest 10-year average Segment Active Shares significantly outperform, with an annualized alpha of $1.4 \%$ (t-statistic of 4.11). Funds with the lowest 10-year average Segment Active Shares perform similarly to the overall market. The abnormal return of the quintile portfolio with funds with the highest 10-year average Segment Active Shares in Table 6, 1.4\% per year, points toward considerably stronger outperformance than the difference of $0.8 \%$ per year between its mean return $(7.4 \%$ per year, see column 2 of Exhibit 7) and the mean market return (6.6\% per year, see column 2 of Exhibit 2). This can be explained by the lower systematic exposure of the highest quintile to the overall real estate 
market as estimated in Exhibit 8, with a beta that is $10 \%$ lower than the overall fund. As a result, the regressions estimates the highest quintile portfolio to be less risky than the overall real estate market, which increases the proportion of its return that cannot be attributed to systematic risk but may rather bring diversification benefits. We thus conclude that our main results are robust to ignoring time variation of Segment Active Shares for particular funds over time.

\section{Exhibit 8. Abnormal Performance of the 10-Year Average Segment Active Share Quintile Portfolios}

The table reports the abnormal performance of five quintile portfolios sorted according to their 10-year average Segment Active Share (in columns $1-5$ ), as well as the results for a long-short portfolio ('Q5 $\mathrm{Q} 1$ ', see column 6) that buys the highest 10-year average Segment Active Share portfolio (Q5) and sells the lowest 10-year average Segment Active Share portfolio (Q1). We only use funds with available data over the full 10-year period. See Exhibit 4 for further description.

(1)

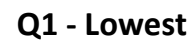

10-Year

Average

Segment

Active Share
(2)

Q2

$1.006^{* * *}$

(60.10)

0.0677

(0.99)

40

0.995

40
(3)

Q3

$1.086^{* * *}$

(107.52)

$-0.251 * * *$

$(-7.16)$

(3)

(2)

Q3

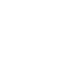

(1)

(4)

(5)

(6)

\begin{tabular}{lcccccc}
$\mathrm{N}$ & 40 & 40 & 40 & 40 & 40 & 40 \\
$\mathrm{R}-\mathrm{sq}$ & 0.995 & 0.997 & 0.984 & 0.982 & 0.979 & 0.304 \\
\hline
\end{tabular}

However, the abnormal return estimate of the portfolio of most active funds is higher when we incorporate changes in Segment Active Shares (annualized alpha of the highest quintile of $1.9 \%$ in Table 2 versus $1.4 \%$ in Exhibit 8 ). This is consistent with the most active funds outperforming, with some time variation in which those most active funds are. To give a sense of how stable Segment Active Shares are across time, we can compare the quintile portfolio sortings across 5 year periods. At the beginning of 2002, our sample consists of 156 funds with available data, out of which 31 funds are sorted into the highest Segment Active Share quintile. Five years later, 11 of those funds are no longer included in the sample. Of the 20 that remain in the sample five year later, 9 funds are still in the highest Segment Active Share quintile (Q5), 5 
moved to the second highest quintile (Q4), 3 moved to Q3 and 3 moved to Q2. Ten years later, 15 funds remain - which are thus included in the sample of funds for which data over the full time period are available. Out of those 15 real estate funds, 6 are still in the highest Segment Active Share quintile (Q5), 3 moved to Q4, 3 moved to Q3, 1 moved to Q2 and 1 moved to Q1.

With the data available to us, we are unable to say whether the funds with the highest Segment Active Share scores rotate segments, seeking out markets and sectors where gains may be found or if segment weights in these funds are stable. This would be a valuable extension for future research, since it would help to untangle whether the outperformance came from informational advantages and skills that related to particular parts of the commercial real estate market or came from more active return-seeking investment strategies. The fund returns reported do account for transaction costs, should the latter be the case. Another fruitful area for research might be to observe whether fund inflows for open ended funds force managers to broaden the segments in which they invest, reducing their Segment Active Share score. This would be consistent with the observed size relationships in our data but cannot be tested directly.

\section{Conclusion}

In this paper, we use a large proprietary dataset from the Investment Property Databank (IPD) with detailed information on the holdings and performance of 256 U.K. commercial real estate funds over 2002 - 2011. With this unique dataset, we provide several contributions to the literature studying the performance of commercial real estate funds.

Our first contribution is methodological, by introducing a holdings-based measure of the degree of active management termed the Segment Active Share, which measures how different fund allocations are across 10 segments from the average market allocation, where high Segment Active Shares indicate significant (i.e., more active or concentrated) segment bets relative to the market. Our measure follows the security-level Active Share measure introduced in Cremers and Petajisto (2009). They document that equity mutual funds with high Active Share - i.e. funds whose holdings are most different from the holdings of their benchmarks outperform. We adapt their security-level measure to the real estate market by aggregating 
portfolio weights across properties in the same segment. The funds in our sample have an average Segment Active Share of $47 \%$, with substantial cross-sectional variation.

Our second contribution is empirical. Sorting funds into five quintile portfolios depending on their Segment Active Share, we find that real estate funds in the highest Segment Active Share quintile significantly outperform. An initial investment of $£ 100$ in the overall aggregated real estate market portfolio at the beginning of our ten-year time period would have been valued at $£ 186$ at the end of the period, generating an average return of $6.4 \%$ per year. An initial f100 investment in the quintile portfolio with the highest Segment Active Share funds would have had a value of $£ 216$ after 10 years, i.e. an average return of $8.0 \%$ per year. This outperformance is also statistically significant, which we establish by calculating the abnormal performance using a regression of the 40 quarterly returns of each portfolio on the average or market return. The quintile portfolio with highest Segment Active Share has an annualized alpha of $1.9 \%$ with a t-statistic of 4.77 , indicating that the outperformance is statistically quite strong.

Next, the outperformance of the most active funds is not accompanied by higher risk, where we consider total volatility, systematic risk or exposure to the overall real estate market portfolio, and finally downside risk or the maximum cumulative loss sustained during the recent global financial crisis.

While high Segment Active Share funds on average hold fewer and smaller properties, their outperformance cannot be explained by the size of the fund, either large or small. We find that if we only consider fund size and ignore Segment Active Share, the group of funds with smallest fund size underperformed. In addition, we find that Segment Active Share scores are fairly stable over time, such that implementing a strategy of focusing investment on high Segment Active Share funds seems practical.

Our finding that commercial real estate fund managers who are more willing or able to depart from market segment weights created most value for their investors suggests that these managers on average have the skill either to identify which segments offer superior value or that they managers may have an informational advantage in certain segments. This is also consistent with the results in Kacperczyk, Sialm and Zheng (2005), whose industry concentration measure is quite similar to the Segment Active Share measure used in this paper. Kacperczyk, Sialm and 
Zheng (2005) document that all-equity U.S. mutual fund manager holding portfolios concentrated in a few industries outperform. We conclude that fund managers with high Segment Active Share indeed seem to have skill together with the courage of their convictions and faced with fewer constraints in implementing their investment strategy.

\section{References}

Andonov, Aleksandar, Rob Bauer and Martijn Cremers, 2013, Can Large Pension Funds Beat the Market? Asset Allocation, Market Timing, Security Selection and the Limits of Liquidity, working paper, University of Notre Dame

Alcock, Jamie, Andrew Baum, Nicholas Colley and Eva Steiner, 2013 forthcoming, The Role of Financial Leverage in the Performance of Private Real Estate Funds, Journal of Portfolio Management, forthcoming.

Bond, Shaun and Paul Mitchell, 2010, Alpha and Persistence in Real Estate Fund Performance, Journal of Real Estate Finance and Economics, 41, 53-79.

Brounen, Dirk, Piet Eichholtz and David Ling, 2007, Trading Intensity and Real Estate Performance, Journal of Real Estate Finance and Economics, 35, 449-474.

Brown, Stephen and Will Goetzmann, 1995, Performance Persistence, Journal of Finance, 50, 679-698.

Callender, Mark, Steven Devaney, Angela Sheahan and Tony Key, 2007, Risk Reduction and Diversification in UK Commercial Property Portfolios, Journal of Property Research, 24, 355-375.

Cremers, K.J. Martijn, and Antti Petajisto, 2009, How Active is Your Fund manager? A New Measure that Predicts Performance, Review of Financial Studies, 22, 3329-3365.

Devaney, Steven and Colin Lizieri, 2005, Individual Assets, Market Structure and the Drivers of Return, Journal of Property Research, 22, 287-307. 
Devaney, Steven and Roberto Martinez Diaz, 2011, Transaction Based Indices for the UK Commercial Real Estate Market: An Exploration Using IPD Transaction Data, Journal of Property Research, 28, 269-289.

Hahn, Thea, David Geltner and Nori Gerado-Lietz, 2005, Real Estate Opportunity Funds, Journal of Portfolio Management, 32 (5), 143-153.

Hartzell, Jay, Tobias Mühlhofer and Sheridan Titman, 2010, Alternative Benchmarks for Evaluating Mutual Fund Performance, Real Estate Economics, 38, 121-154.

IPD, 2012, IPD UK Quarterly Digest Q4 2011, London: Investment Property Databank.

Kacperczyk, Marcin, Clemens Sialm, and Lu Zheng, 2005, On the industry concentration of actively managed equity mutual funds, Journal of Finance 60, 1983-2011.

Lee, Stephen and Steven Devaney, 2007, The Changing Importance of Sector and Regional Factors in Real Estate Returns, Journal of Property Research, 24, 55-69.

Property Industry Alliance, 2012, Property Data Report 2011, London: Property Industry Alliance 